\title{
Cutis verticis gyrata : An interesting cutaneous finding in acromegaly
}

Tripathi $M^{1}$, Mukherjee $K K^{2}$

${ }^{1}$ Senior Resident, Department of Neurosurgery, Postgraduate Institute of Medical Education and Research, Chandigarh, India; ${ }^{2}$ Additional Professor, Department of Neurosurgery, Postgraduate Institute of Medical Education and Research, Chandigarh, India

\author{
Address for correspondence \\ Dr. Manjul Tripathi \\ Senior Resident \\ Department of Neurosurgery \\ Postgraduate Institute of Medical Education and Research, Chandigarh, India \\ Email: drmanjultripathi@gmail.com
}

Cutis verticis gyrata $(\mathrm{CVG})$ is a descriptive term given for a condition of scalp in which there is gross thickening of the scalp along with convoluted furrows and folds. This condition was first described by Albeit in 1837. Patients, (A) 35 years and (B) 62 years old, presented with acromegaly and hypogonadism. There was excessive thickness of scalp with the formation of cerebriform pattern convolutions (Figure 1). It was cosmetically bothersome for the patient (A). There were visible cerebriform folds on the scalp which were not corrected with pressure. The clinical presentation was consistent with secondary form of CVG, that is seen in cases of acromegaly. ${ }^{1}$ The number of folds may vary and are typically soft and spongy. The disease predominantly affects males in the ratio of 5-6:1.
CVG can be primary or secondary. Primary essential CVG is of unknown etiology. The secondary cases of CVG are frequently associated with acromegaly, pseudoacromegaly, graves disease, amyloidosis, Ehlers Danlos syndrome and inflammatory processes like melanocytic naevi, eczema, psoriasis, folliculitis, darier disease, impetigo and use of Minoxidil. CVG may also be due to increased peripheral use of testosterone. ${ }^{2}$ Lymphedema is a postulated cause of CVG in Turner and Noonan syndrome. ${ }^{3}$ The disease is long lasting and progressive. It is often found to be unacceptable because of cosmetic reasons. The treatment consists of local hygiene and surgical resection of excess skin, only if cosmetically bothering. ${ }^{4}$

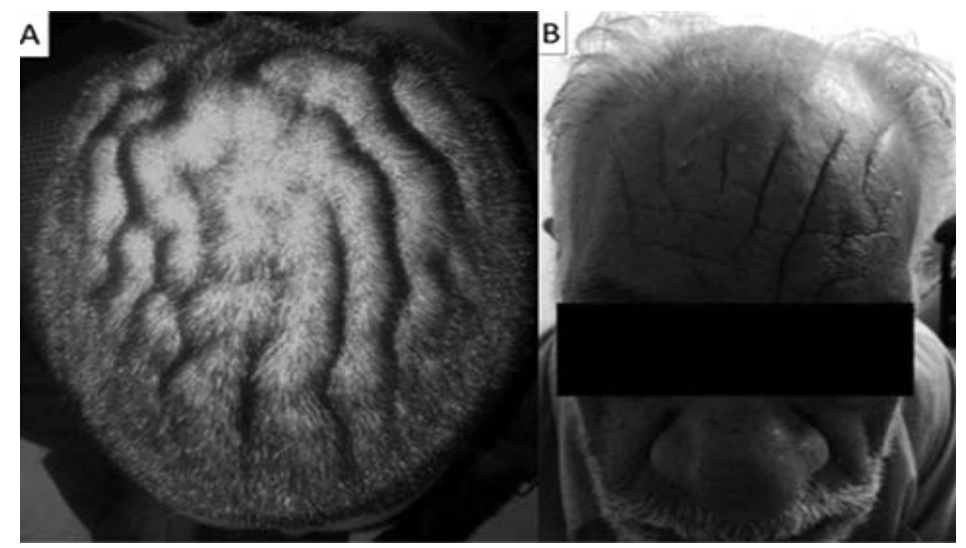

Figure 1 (A, B): Hypertrophy and folding of the skin of scalp giving rise to a cerebriform or gyrate appearance. 


\section{Letter to Editor}

\section{References}

1. O'Reilly FM, Sliney I, O'Loughlin S. Acromegaly and cutis verticis gyrata.. J R Soc Med 1997; 90: 79.

2. Palazzo R, Schepis C, Ruggeri M, Baldini L, Pizzimenti A, Arcoraci V et al. Acta Derm Venereol 1993; 73: 348-9.

3. Fox LP, Geyer AS, Anyane Yeboa K, Garzon MC. Cutis verticis gyrata in a patient with Noonan syndrome. Pediatric Dermatology 2005; 22: 142-6. http://dx.doi.org/10.1111/j.15251470.2005.22211.x

4. Radwanski HN, Almeida MW, Pitanguy I. Primary essential cutis verticis gyrata - a case report. J Plast Resconstr Aesthet Surg 2009; 62: e430-3. http://dx.doi.org/10.1016/j.bjps.2008.06.062 